\title{
Why did mainstream economics miss the crisis? The role of epistemological and methodological blinkers
}

(draft October 25, 2011)

\section{Why economics needs to predict}

The financial crisis that hit high-income economies in 2008 has had a depressive economic impact around the globe, which has been compared to the recession of the 1930s. It is damaging many people's well-being in terms of growing unemployment and increasing insecurity for those fortunate enough to keep their employment. In 2010, there were 27.6 million more unemployed people in the world as compared with 2007. Similarly, the numbers of people in vulnerable employment have been rising (ILO, 2011: 6ff). Comparative analysis of financial crises since the mid-1990s (van der Hoeven, 2011) and current projections for these indicators for 2011 (ILO, 2011) give reason to fear that the human costs of the crisis will continue to be high.

Despite the use of sophisticated forecasting models, neo-classical economics did not foresee a crisis of this global scale. The International Monetary Fund's (IMF's) annual "World Economic Outlook" is widely quoted as a source for analyses and predictions of the global economic climate. It is prepared by the Fund's large crew of economists, trained chiefly in the neo-classical tradition. In the outlook's April 2007 edition, one and a half year before the bankruptcy of Lehman Brothers became the starting signal of the so-far deepest and broadest financial and economic crisis ever, the difficulties in the US housing sector were being acknowledged, but "the baseline view remains that difficulties in the housing sector will not have major spill-overs, provided that employment and income growth remain resilient.” (IMF, 2007: 7f).

Though the US housing sector faced problems, this was in a period of rapid global economic growth and the US-specificity of the phenomenon encouraged the view that developments in the USA would 'decouple' from the global economy (IMF, 2007: xvi). The widely predicted 2008 annual GNP growth rate for the USA stood at 2.8 per cent, compared to an actual increase of 0.4 per cent in 2008 and a slump of -2.4 per cent in 2009 (IMF, 2010). But, focusing on empirical data on the US housing market, forecasts missed the deeper structural processes taking place in the financial sector that would spread the crisis globally.

The response to the global financial crisis has been characterised by an unusual degree of self-criticism of the economists profession for not foreseeing this shock (e.g. Krugman, 2009, Colander et al., 2009). This was despite prediction being claimed to be the main objective of the discipline by Milton Friedman, the Nobel Laureate and doyen of neo-classical economics in 1953. In an essay that has been called the most influential work on economic methodology in the 20th century, Friedman defined the aim of 'positive' - in contrast to normative - economics as 'to provide a system of generalisations that can be used to make correct predictions about the consequences of any change in circumstances' (Friedman, 1953: 181).

In this paper, we show how the anchoring of methodologies associated with neoclassical economics in a logical positivist epistemology has prevented economists from detecting cusps in the economy. With neo-classical economics, we refer to a 
narrow understanding of the discipline that emerged in the late $19^{\text {th }}$ century in the work of Jevons, Menger and Walras associated with mathematisation of economics. The related economic policy advice centres on the advocacy of letting competitive market forces allocate resources. We argue that, while the depression of the 1930s had led to an overhaul of discipline's theoretical foundations, giving way to Keynes' acknowledgement of the persistence of market disequilibria, the financial crises of the past 20 years ought to initiate a questioning of the epistemological foundations of the discipline. As an alternative, we offer our interpretation of a critical realist underpinning for a political economy focused on the specific instabilities of contemporary global capitalism.

\section{The logical positivist roots of neo-classical economics}

Economics has aspired to the status of a predictive science since Adam Smith claimed to have discovered laws in the operation of markets (e.g. Hirshleifer, 1985, Sebba, 1953). The 'invisible hand' of market forces can be seen as having an epistemological equivalence to Isaac Newton's force of gravity (e.g. Redman, 1993), including its ability to bring 'bodies' into interaction at a distance with no physical links. The desire to emulate 'natural sciences' epistemology was understandable as puzzle after puzzle appeared to be solved in physics using a combination of deductive logic and careful observation.

Karl Popper modified our understanding of the success of physics as knowledge and extended his epistemology of science in the physical world to knowledge of human phenomena. Proposing falsification as the 'solution' to the induction problem in knowing the physical world, Popper suggested that all human knowledge was provisional (Popper, 1972). His starting point was the asymmetry between verification and falsification: While nothing can ever be exhaustively empirically verified - the 'problem of induction' had been recognised since Hume in the 18th century -, a single empirical falsification suffices to disprove an empirically testable statement (Blaug, 1994: 111). According to Popper, this falsification criterion distinguishes science from non-science (Blaug, 1994: 109f, Boland, 1994: 155). He laid down conventions to prevent scientists from safeguarding refuted theories. Their main idea is that refuted theories may be amended to avoid future falsifications, but only if they increase the empirical content of the theory and hence render it more testable (Blaug, 1994: 111).

Other epistemological virtues were added to complete a logical positivist epistemological paradigm. The emphasis on deductive work suggested there was a virtue in reducing the ontological weight of assumptions from which the deductive work proceeded. Therefore, the parsimony of Occam's razor was attractive in epistemologically ranking theories making the same prediction with fewer assumptions above those with more assumptions. One valued quality of these assumptions was mathematical tractability to facilitate rigorous deduction.

The emphasis on falsification and deductive work (and the academic prestige that went with it) had implications for the epistemological virtues of observation. Deductive work became scientific when it resulted in falsifiable predictions of observable relationships that seemed to reveal natural laws. Therefore, 
epistemologically virtuous predictions possessed the qualities of both precision and generalisation.

\section{Why neo-classical economics fails to predict}

The translation of the logical positivist epistemology outlined above into neo-classical economics has had profound, if complex, methodological consequences. They include an emphasis on falsification as a key criterion for assessing the quality of knowledge, translated into quantified research procedures, thin models of human agency and collective economic behaviour as well as the exogenisation of dramatic change outside the economic domain. Together, these methodological implications overdetermine an inability to predict cusps and their associated crises.

In neo-classical economics, stochastic hypothesis testing has become the methodological corollary of falsification tests in Popperian science. To paraphrase Einstein, 'in neo-classical economics, god does play dice'. While it does not require a quantitative approach, applied economics research commonly employs analytical statistics of historical quantitative data for hypothesis testing. Generalisation in economics became associated with statistical significance tests on random samples from well specified populations. The significance of coefficients is used as an indicator of whether models are supported or rejected by empirical data (McCloskey and Ziliak, 1996).

Stochastic testing resists unambiguous falsification and can permit theories to persist merely because they have not been falsified, rather than because they give insights into actual events. The dynamic stochastic general equilibrium (DSGE) models widely used by Central Banks for macro-economic forecasting are cases in point. They have been criticised for being too simplistic (Colander et al., 2008). Even researchers at the Bank for International Settlements have pointed out that one of the major limitations of DSGE models is their weakness in modelling financial markets (Tovar, 2009: 6ff). Neither this critique nor their failure to predict the crisis has led to their abandonment.

As an important side effect, the quantitative or quantifiable information that is required for econometric testing, converts information about structures and institutions in an economy to categorical, ‘dummy' or 'proxy' variables. Complex regulation of financial markets, albeit important in influencing the behaviour of economic actors, is difficult to translate into a parameter of general equilibrium models, though. Hence, the aim of identifying generalisable laws and the use of historical, numerical data combine to produce a tendency to predictions emphasising extrapolation from stable 'structural' relationships, constraining the capacity to foresee discrete changes.

Models of human agency in its economic dimension realm are commonly based on the assumption of individual choice at the margin, underpinned by an axiomatic economic rationality (Bardhan and Ray, 2006) that reduces the future to a calculation of expected values and rational expectations. This ontological, atomistic status given to the 'axiomatically rational individual' in mainstream neo-classical economics owes its origins to a complex mix of 'modernist' liberal ideology and mathematical 
tractability. But a possible model of Nietzschean 'heroic' human agency in which individuals exercise full self-determination is constrained to only allow individual choices at the margin in response to gradual movements in the vector of all prices. Such a 'thin theory of human action' (Taylor, 1988) is assumed to give economic models their precision, parsimony and predictive power, criteria very much in line with Popperian thinking. Changes due to technological innovation are treated as gradually disseminating and absorbable at the margin in decision-making. Large unanticipated challenges would destroy the generalisable patterns that are the objective of Friedmannian scientific inquiry, and are therefore being missed out in this approach (Rattagia, 2010: 29).

Besides the thin conceptualisation of human agency underlying neo-classical economics, methodological individualism also implies that macro-events are largely perceived as being (caused by) aggregates of individual actions with limited interactive variables. The structure of general equilibrium mathematical economic models allows to take into account large numbers of prices, commodities, and - last but not least - agents (Debreu, 1991). In case of the DSGE models, this assumes away, for instance, any agent coordination problems or emergent macro properties. Colander et al. (2008: 236) conclude that "Since in a complex system aggregate behavior cannot be deduced from an analysis of individuals alone, representative agent models fail to address the most basic questions of macroeconomics.”

This implies the inability to foresee the consequences of non-marginal changes, such as rapid, apparently unconstrained changes in asset values that render 'negative feedback' predictive models based on rational expectations and expected values redundant. Tendencies to emphasising equilibrium, comparative static approaches to change, and positivist quantified empiricism are emergent phenomena from this epistemological and methodological framing that can also contribute to failure to predict crisis.

Friedman's distinction between the realms of positive and normative economics, with the latter being an arena for politicians rather than for serious economists, parallels Popper's distinction between science and non-science. It has led to an exogenisation of dramatic change outside the economic domain, reflected, for instance, in the explanation that politicians 'caused' the problems by irresponsible fiscal policies and/or 'rescuing' banks that 'should' have been allowed to fail. Yet, the neo-classical assumption of equilibrating force of markets actually leads to a strong normative position of minimising extra-economic interference and a demand for less regulation.

But how do these methodological principles obstruct prediction? The answer is subtle, it appears that logical positivism places an emphasis on abstract logical reasoning which should free up thinking about possible futures. But the demand that the logical process leads to falsifiable predictions tested against already existing data means that claims to new knowledge are inevitably backward looking. Thus predictions about the future are mere extensions of the past consistent with the deep ontological belief that the past and the future are fundamentally similar reflecting the same equilibrating processes. In the physical sciences, the assumption of fundamental symmetry between the past and the future with both governed by the same natural laws has not proved problematic, but predicting movements in the human condition may require an approach that permits cusps, disjunctures, and crises. 


\section{The critical realist alternative in making predictions}

As an alternative to this epistemological/methodological nexus, we offer our interpretation of a critical realist underpinning for a political economy focused on the specific instabilities of contemporary global capitalism. Critical realism conceptualises reality as open and layered. It assumes openness in the sense that the social world is characterised by relations and dependencies between people and institutions as well as by the possibility for internal change (Lawson, 1997: 77ff). Bhaskar (2008: 46ff) distinguishes the 'real' level of reality from the 'actual' and the 'empirical'. While the real refers to causal structures and generative mechanisms, it generates events at the actual level, which are apprehended as experiences in the domain of the empirical. Epistemologically, this implies that the aim of social science cannot go beyond the identification of event demi-regularities in empirical data, embedded and caused in the specific 'real' social and historical settings (Lawson, 1997: 204f). As causal powers are located at the level of the real, a more appropriate causal analysis takes into account theoretical knowledge of underlying structures and the historical analysis of the particular circumstances in which they exist (Bhaskar, 1986: 108). This logic of inference espoused by critical realism has been termed 'retroduction' (Danermark et al., 2002: 96ff).

In constructing an alternative, we return to the limitations of neo-classical economics methodology described above and systematically modify them in a critical realist direction.

a. Less emphasis on falsification as a key criterion for assessing quality of knowledge

b. More space for non-quantified reflections on relationships

c. Thicker model of human agency, including bounded rationality and uncertainty

d. Well-specified model of collective human economic behaviour

e. Endogenise the possibility of dramatic change within the economic domain

Using this antithetical framework, we suggest that an economics methodology informed by a critical realist epistemology would increase the probability of a timely prediction of crises.

a. Critical realism values structural explanation (retroduction) in place of hypothesis testing at the, often superficial, empirical level. Starting from an ontological position that reality is layered, going beyond observable, atomistic data, knowledge should be assessed in terms of its claims to integrate all human experience into a single, complex framework, including the potential for multi-dimensional, integrated crisis

b. The search for generalisable economic laws through falsification presumes event regularities. This assumption has been criticised by critical realists as imposing an unrealistic external closure on a reality that is essentially open (Lawson, 1997: 77ff, Sayer, 1992: 182ff). Moreover, because the observation of events does not enable the 
identification of their causes due to the disjuncture between real structures, the actual events produced and the restricted range of events that is available to experience (Gruffydd Jones, 2001: 3), critical realist contributions have criticised analytical statistics alone as inappropriate for the explanation of social phenomena. Deprioritising quantitative data reduces the temptation to extrapolate and impose path dependence. Mixed-methods triangulation, in contrast, has been identified as a manifestation of retroduction that allows a logically consistent approach to economic analysis (Downward and Mearman, 2007: 96).

c. Critical realists have criticised the intrinsic closure of economic models, assuming an automatic transmission of a set of boundary conditions or events into another measureable event mediated by the abovementioned 'thin' model of human agency. The critical realist emphasis on openness lends itself to a more ethnographic, lifeworld approach to human identity and decision-making rather than models of representative agents derived from introspection rather than from empirical evidence.

d. A broader approach to human decision-making may travel beyond individuals as decision-making unit. Taking a critical realist perspective, Andrikopoulos (2011: 15) emphasises that the 'social nature of financial markets' due to participants' practices and conventions, their structured relations as well as the fact that financial markets are constitutive parts of the society's culture exclude the possibility of closure and constant regularities. While much data at the empirical level is collected from individuals (people or firms), the actual and structural levels of critical realism create room for creating analytical collectivities, such as classes and fractions of capital. Many critical realist contributions claim that reality is dialectical and in a perpetual state of change caused by unresolved structural tensions. In contrast to a theoretical emphasis on the equilibrating forces of markets, this awareness of tension increases the possibility of foreseeing crises.

e. The openness of reality that is an ontological and epistemological point of departure for critical realists implies that there are no clear boundaries between economics and politics. In critical realism, changes in structural processes in any field can spread throughout a system changing all other fields. Structural changes in the economic field can induce emergent changes in the political field at the actual level. Lawson (2009: 774) summarises that “At all points in, and stages of development of, the financial system, we are faced not with a ubiquity of regular behavioural patterns underpinned by isolated systems of human atoms, but with the perpetual emergence of novelty, not least at the level of relational structures, underpinning transformed mechanisms and practices.” Therefore, decisions in formal politics are likely to be de facto shifting responsibility for crisis from economic structural processes to the political field at the actual level

\section{Applying critical realist principles to the current crisis}

In the realm of financial markets, the domain of the empirical may refer to data on asset prices, while the actual would address the event of asset pricing, triggered by the real structures of regulation and financial market actors' strategies. In contrast to the causality established between data in the empirical domain that characterises logical positivism - 'event regularities' in critical realist parlance - critical realism aims at 
explanation that takes the causal powers of the real level as a starting point and aims at an identification of how they work and under what conditions (Sayer, 1992: 14).

Andrikopoulos (2011: 26f) argues that "[a]n alternative approach can assume open systems that conform with the absence of constant regularities in observed instances of market operation, such as asset prices, leverage ratios or credit ratings. In such an approach, the symmetry between explanation and prediction would not necessarily hold and reality should be sought on the level of mechanisms and powers that cause the financial events, not only on the conjunction of financial events, like the data generating processes of stock prices”.

Thus, the empirical underpricing of financial risk that paved the way for the current economic crisis can be seen as crucially influenced by institutional scenery and actors with bounded rationality acting on the structural stage provided by global capitalism. They included the role of rating agencies who both determined the risk of collateralised debt obligations and advised banks on how to structure them, as well as of banks' strategies to reduce the assets held as buffer against losses (Lawson, 2009: 768ff). An international regulatory framework for banks that 'outsourced' the institutional determination of regulating capital to firms' internal forecasting models contributed to increase risks for the general economy overflowing from the financial institutions (Rattagi, 2010: 11). This contagion was not weakened by dampening negative feedback from the operation of market forces, but was strengthened by actual boundedly rational herd behaviour - very different from the processes posited by neoclassical economics models of individual rational behaviour in orderly markets.

Predicting the crisis requires qualitative analysis of dialectical structural processes of global capitalism with a potential for chronic instability - a number of alternative structural models exist within broadly defined political economy, including current models of co-existing varieties of capitalism (Boyer, 2011, Streeck, 2011). Analysing these processes requires identifying agency in collective conceptual categories (acting with a group consciousness) that may include national governments, but will involve other collectivities, notably, in the current crisis, an analytical category of collective behaviour by financial institutions operating at the actual level of critical realist knowledge creation (Kalinowski, 2011).

\section{References}

Andrikopoulos, A. (2011) 'Finance: An Essay on Objects and Methods of Inquiry', June 23-25, 2011. Society for the Advancement of Socio-Economics (SASE).

Bardhan, P. and I. Ray (2008) 'Methodological Approaches in Economics and Anthropology', in J. B. Davis and W. Dolfsma (eds) The Elgar Companion to Social Economics, pp. 427-444. Cheltenham; Northhampton: Edward Elgar Publishing.

Bhaskar, R. (2008) A Realist Theory of Science. Milton Park, New York: Taylor \& Francis.

Bhaskar, R. (1986) Scientific Realism and Human Emancipation. London: Verso. 
Blaug, M. (1994) 'Why I Am Not a Constructivist. Confessions of an Unrepentant Popperian', in R.E. Blackhouse (ed.) New Directions in Economic Methodology, pp. 109-136. London; New York: Routledge.

Boland, L. (1994) 'Scientific Thinking without Scientific Method: Two Views of Popper', in R.E. Backhouse (ed.) New Directions in Economic Methodology, pp. 154172. London; New York: Routledge.

Boyer, R. (2011) 'Are there laws of motion of capitalism?', Socio-Economic Review, 9 (1): 59-82.

Colander, D., M. Goldberg, A. Haas, K. Juselius, A. Kirman, T. Lux et al. (2009) 'The Financial Crisis and the Systemic Failure of the Economics Profession', Critical Review 21(2-3): 249-267.

Colander, D., P. Howitt, A. Kirman, A. Leijonhufvud and P. Mehrling (2008) 'Beyond DSGE Models: Toward an Empirically Based Macroeconomics', The American Economic Review 98(2): 236-240.

Danermark, B., M. Ekstroem, L. Jacobsen and J.C. Karlsson (2002) Explaining Society: Critical Realism in the Social Sciences. Milton Park, New York: Psychology Press.

Debreu, G. (1991) 'The Mathematization of Economic Theory', The American Economic Review 81(1): pp. 1-7.

Downward, P. and A. Mearman (2007) 'Retroduction as Mixed-Methods Triangulation in Economic Research: Reorienting Economics into Social Science', Cambridge Journal of Economics 31(1): 77-99.

Friedman, M. (1953) 'The Methodology of Positive Economics', in D.M. Hausman (ed.) The Philosophy of Economics: An Anthology, Vol. 2. pp. 180-213. Cambridge: Cambridge University Press.

Gruffydd Jones, B. (2001) 'Explaining Global Poverty: A Realist Critique of the Orthodox Approach', Journal of Critical Realism, Alethia 4(1): 2-10.

Hirshleifer, J. (1985) 'The Expanding Domain of Economics', The American Economic Review 75(6): 53-68.

Hoeven, R. van der (2011) 'Financial Globalization, Current Crisis and Labour in Developing Countries', in P.A.G. van Bergeijk, A. de Haan and R. van der Hoeven (eds) The Financial Crisis and Developing Countries: A Global Multidisciplinary Perspective, pp. 127-143. Cheltenham, UK; Northampton, MA, USA: Edward Elgar.

International Labour Organization (ILO) (2011) Global Employment Trends 2011: The Challenge of a Jobs Recovery. Geneva: ILO.

International Monetary Fund (IMF) (2010) World Economic Outlook April 2010: Rebalancing Growth. Washington DC: IMF. 
IMF (2007) World Economic Outlook April 2007: Spillovers and Cycles in the Global Economy. Washington DC: IMF.

Kalinowski, T. (2011) 'Regulating international finance and the evolving imbalance of capitalisms since the 1970s’, MPlfG Discussion Paper 11/10, Cologne: Max Planck Institute for the Study of Societies.

Krugman, P. (2009) 'How did Economists Get it so Wrong?' New York Times, September 6, 2009.

Lawson, T. (2009) 'The Current Economic Crisis: Its Nature and the Course of Academic Economics', Cambridge Journal of Economics 33(4): 759-777.

Lawson, T. (1997) Economics and Reality. London; New York: Routledge.

McCloskey, D.N. and S.T. Ziliak (1996) 'The Standard Error of Regressions', Journal of Economic Literature 34(1): 97-114.

Popper, K. (1972) Objective Knowledge: An Evolutionary Approach. Oxford: Clarendon Press.

Rattaggi, M.L. (2010) 'Crisis and Models: What should we Learn?'. Cambridge: University of Cambridge.

Redman, D.A. (1993) 'Adam Smith and Isaac Newton', Scottish Journal of Political Economy 40(2): 210-230.

Sayer, A. (1992) Method in Social Science. (2nd edn). New York: Routledge.

Sebba, G. (1953) 'The Development of the Concepts of Mechanism and Model in Physical Science and Economic Thought', The American Economic Review 43(2): 259-268.

Streeck, W. (2011) 'Taking capitalism seriously: towards an institutionalist approach to contemporary political economy', Socio-Economic Review 9(1): 137-167.

Taylor, M. (1988) 'Rationality and Revolutionary Collective Action', in M. Taylor (ed.) Rationality and Revolution, Cambridge: Cambridge University Press.

Tovar, C.E. (2009) 'DSGE Models and Central Banks', Economics: The Open-Access, Open-Assessment E-Journal 3(16): 1-31. 